Authors have nothing to disclose with regard to commercial support.
Sibtain Anwar, MBBS, FRCP, FRCA, PhD

St Bartholomew's Hospital

London, United Kingdom

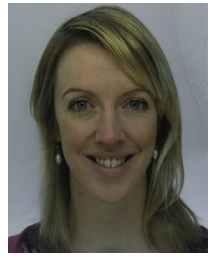

\section{THE ROLE OF HYPEROXIA IN CARDIAC ENHANCED RECOVERY PROGRAMS}

\section{To the Editor:}

We would like to thank the authors of "One-Year Results From the first US-Based Enhanced Recovery After Cardiac Surgery (ERAS Cardiac) Program" "1 for highlighting the feasibility of such a program. However, we did wonder about a key component of the ERAS Cardiac Protocol.

As part of intraoperative infection prophylaxis, the authors have suggested a fraction of inspired oxygen of $>0.8$. Although the World Health Organization encouraged this in 2016 to reduce postoperative surgical-site infections, subsequent opinions dispute this. ${ }^{2}$ Certainly, a recent meta-analysis concluded that this guidance was based on flawed studies, and that the use of hyperoxia could in fact prove detrimental. ${ }^{3}$ It would be interesting to know what prompted the authors to include hyperoxia as part of their ERAS protocol. Current practice suggests that the harm of hyperoxia may outweigh any benefit. ${ }^{4}$

In addition, although the point of protocols is to standardize pathways of care, we would be wary of implementing such a regime at our institution for fear of impacting current standards and financial constraints. Patient-centered outcomes as well as evidence of generalizability, flowing from the experience of multiple centers, would strengthen this case. Most importantly the health economic benefits of such an intervention would need to be clear.

However, the study does highlight the importance of a holistic postoperative bundle of care, eg, use of antiemetics and mobilization. As clinicians, we often fail to do the simple things well-and these often make the most memorable difference to a patient's experience-and we are therefore grateful to the authors and the Journal for this reminder.

Heather Storey, MBBS, BSc, FRCA Simon Stacey, MBBS, FRCA, FFICM

\footnotetext{
The Editor welcomes submissions for possible publication in the Letters to the Editor section that consist of commentary on an article published in the Journal or other relevant issues. Authors should: • Include no more than 500 words of text, three authors, and five references. • Type with double-spacing. • See http://jtcs.ctsnetjournals.org/ misc/ifora.shtml for detailed submission instructions. • Submit the letter electronically via jtcvs.editorialmanager.com. Letters commenting on an article published in the JTCVS will be considered if they are received within 6 weeks of the time the article was published. Authors of the article being commented on will be given an opportunity of offer a timely response ( 2 weeks) to the letter. Authors of letters will be notified that the letter has been received. Unpublished letters cannot be returned.
}

\section{References \\ 1. Williams JB, McConnell G, Allender JE, Woltz P, Kane K, Smith PK, et al. One-year results from the first US-based enhanced recovery after cardiac surgery (ERAS Cardiac) program. J Thorac Cardiovasc Surg. 2019;157:1881-8. \\ 2. Hedenstierna G, Perchiazzi G, Meyhoff CS, Larsson A. Who can make sense of the WHO guidelines to prevent surgical site infection? Anesthesiology. 2017; 126:771-3. \\ 3. Myles PS, Carlisle JB, Scarr B. Evidence for compromised data integrity in studies of liberal peri-operative inspired oxygen. Anaesthesia. 2019;74:573-84. \\ 4. Horncastle E, Lamb AB. Hyperoxia in anaesthesia and intensive care. BJA Education. 2019;19:176-82.}

https://doi.org/10.1016/j.jtcvs.2019.09.152

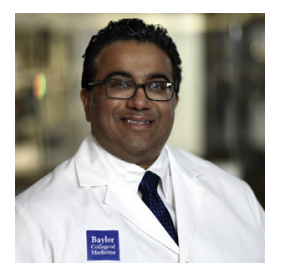

\section{REPLY: IS HYPEROXIA FULL OF HOT AIR? Reply to the Editor:}

In their response to the recent publication by Williams and colleagues $^{1}$ on 1-year results from the first US-based enhanced recovery after cardiac surgery (ERAS Cardiac) program, Storey and colleagues make an astute observation about the role of hyperoxia. The recommendation by Williams and colleagues $^{1}$ to maintain a fraction of inspired oxygen $>0.8$ as part of the "NO BUGS" infection prophylaxis strategy was probably based on the World Health Organization (WHO) 2016 guidelines on intraoperative and postoperative measures for preventing surgical-site infection, which encouraged this strategy in the operating room and for up to 6 hours postoperatively. ${ }^{2}$

The hyperoxia story is an illustrative guide on how compromised data can negatively influence subsequent guideline recommendations. A single researcher from the central Italian University of L'Aquila was forced to retract 4 papers that reported results from randomized controlled trials supporting liberal perioperative oxygen $(80 \%$ vs $30 \%$ ). Noting that these papers had heavily influenced the WHO guidelines, Myles and colleagues ${ }^{3}$ performed a systematic review that excluded those retracted studies and found that the recommendation for liberal perioperative oxygen no longer remained. As Volk and coworkers noted, ${ }^{4}$ the WHO guideline committee did not include any anesthesiologists, and as Storey and her fellow anesthesia colleagues point out, had the committee done so, the recommendation might have been examined more critically.

Nevertheless, it should be noted that in their recently published enhanced recovery guidelines for perioperative care in cardiac surgery, Engelman and colleagues omitted any reference to hyperoxia. Moreover, Grant and colleagues, ${ }^{6}$ in an analysis of their experience in the 
Author has nothing to disclose with regard to commercial support.

Johns Hopkins Enhanced Recovery Program for Cardiac Surgery, also avoided any recommendation for the use of hyperoxia. Thus, the hyperoxia recommendation no longer appears to be influencing enhanced recovery methodology.

Subhasis Chatterjee, $M D$ Divisions of General and Cardiothoracic Surgery Michael E. DeBakey Department of Surgery Baylor College of Medicine

Houston, Tex Department of Cardiovascular Surgery Texas Heart Institute Houston, Tex

\section{References}

1. Williams JB, McConnell G, Allender JE, Woltz P, Kane K, Smith PK, et al. One-year results from the first US-based enhanced recovery after cardiac surgery (ERAS Cardiac) program. J Thorac Cardiovasc Surg. 2019;157:1881-8.

2. Allegranzi B, Zayed B, Bischoff P, Kubilay NZ, de Jonge S, de Vries F, et al. New WHO recommendations on intraoperative and postoperative measures for surgical site infection prevention: an evidence-based global perspective. Lancet Infect Dis. 2016;16:e288-303.

3. Myles PS, Carlisle JB, Scarr B. Evidence for compromised data integrity in studies of liberal peri-operative inspired oxygen. Anaesthesia. 2019;74:573-84.

4. Volk T, Peters J, Sessler DI. The WHO recommendation for $80 \%$ perioperative oxygen is poorly justified. Anaesthesist. 2017;66:227-9.

5. Engelman DT, Ben Ali W, Williams JB, Perrault LP, Reddy VS, Arora RC, et al Guidelines for perioperative care in cardiac surgery: enhanced recovery after surgery society recommendations. JAMA Surg. 2019;154:755-66.

6. Grant MC, Isada T, Ruzankin P, Whitman G, Lawton JS, Dodd-o J, et al. Results from an enhanced recovery program for cardiac surgery. J Thorac Cardiovasc Surg. June 7, 2019 [Epub ahead of print].

https://doi.org/10.1016/j.jtcvs.2019.09.153

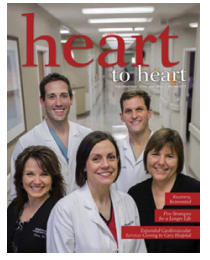

REPLY FROM THE AUTHORS: O IS FOR NORMOXIA

Reply to the Editor:

We thank Drs Storey, Stacey, and Anwar for a thoughtful and important letter. $^{1}$ You are correct in pointing out concerns with hyperoxia being detrimental, and this is our
Authors have nothing to disclose with regard to commercial support.

opinion and practice as well to avoid hyperoxia. With initiation of our enhanced recovery pathway, ${ }^{2}$ we incorporated the World Health Organization "NO BUGS" protocol perioperatively, aiming for normothermia, appropriate antibiotic dosing, avoidance of hypoventilation, glycemic control, and appropriate skin prep. However, we did not incorporate from the original "NO BUGS" protocol the use of hyperoxia. ${ }^{3}$ Intraoperatively, patients were given $100 \%$ oxygen before the induction of anesthesia, potentially during more prolonged periods of breath-holding requested by the surgeon or during periods of hemodynamic instability concerning for poor oxygen delivery to the patient. As you describe, ${ }^{1}$ the World Health Organization changed the recommendation to conditional last year based on the discovery of flawed data. ${ }^{4}$ The icon we used for the flow pathway ${ }^{2}$ was adapted from the 2016 iteration, and we will change the fraction of inspired oxygen recommendation in the illustration. The first "O" in "NO BUGS" for our Enhanced Recovery after Surgery Cardiac Surgery pathway is actually best suited for nOrmoxia.

Judson B. Williams, $M D, M H S^{a}$

William T. Bradford, $M D^{b}$

${ }^{a}$ WakeMed Health and Hospitals

WakeMed Clinical Research Institute

Cardiovascular and Thoracic Surgery

${ }^{b}$ American Anesthesiology of the Carolinas

Raleigh, $\mathrm{NC}$

\section{References}

1. Storey H, Anwar S, Stacey S. The role of hyperoxia in cardiac enhanced recovery programs. J Thorac Cardiovasc Surg. 2020;159:e217.

2. Williams JB, McConnell G, Allender JE, Woltz P, Kane K, Smith PK. One-year results from the first US-based enhanced recovery after cardiac surgery (ERAS Cardiac) program. J Thorac Cardiovasc Surg. 2019;157:1881-8.

3. Hedenstierna G, Perchiazzi G, Meyhoff CS, Larsson A. Who can make sense of the WHO guidelines to prevent surgical site infection? Anesthesiology. 2017; 126:771-3.

4. Myles PS, Carlisle JB, Scarr B. Evidence for compromised data integrity in studies of liberal peri-operative inspired oxygen. Anaesthesia. 2019;74:573-84.

https://doi.org/10.1016/j.jtcvs.2019.09.154 